\title{
Implementation of improvement strategies in palliative care: an integrative review
}

Jasper van Riet Paap ${ }^{1 *}$, Myrra Vernooij-Dassen ${ }^{1,2,3}$, Ragni Sommerbakk ${ }^{4}$, Wendy Moyle ${ }^{5}$, Marianne J. Hjermstad ${ }^{4,6}$, Wojciech Leppert ${ }^{7}$, Kris Vissers ${ }^{8}$, Yvonne Engels $^{8}$ and on behalf of the IMPACT research team

\begin{abstract}
Background: The European population is ageing, and as a consequence, an increasing number of patients are in need of palliative care, including those with dementia. Although a growing number of new insights and best practices in palliative care have been published, they are often not implemented in daily practice. The aim of this integrative review is to provide an overview of implementation strategies that have been used to improve the organisation of palliative care.

Methods: Using an integrative literature review, we evaluated publications with strategies to improve the organisation of palliative care. Qualitative analysis of the included studies involved categorisation of the implementation strategies into subgroups, according to the type of implementation strategy.

Results: From the 2379 publications identified, 68 studies with an experimental or quasi-experimental design were included. These studies described improvements using educational strategies $(n=14)$, process mapping $(n=1)$, feedback $(n=1)$, multidisciplinary meetings $(n=1)$ and multi-faceted implementation strategies $(n=51)$. Fifty-three studies reported positive outcomes, 11 studies reported mixed effects and four studies showed a limited effect (two educational and two multi-faceted strategies).

Conclusions: This review is one of the first to provide an overview of the available literature in relation to strategies used to improve the organisation of palliative care. Since most studies reported positive results, further research is needed to identify and improve the effects of strategies aiming to improve the organisation of palliative care.
\end{abstract}

Keywords: Palliative care, Europe, Implementation, Improvement strategies

\section{Background}

The European population is ageing, and as a consequence, an increasing number of patients are in need of palliative care, including those with dementia. The World Health Organization has defined palliative care as an 'approach to improve the quality of life of patients and families who face life-threatening illness, by providing pain and symptom relief, spiritual and psychosocial support from diagnosis to the end of life and bereavement' [1-3]. Although a growing number of new insights and best practices in palliative care are being published, knowledge translation into daily practice is lacking [4]. Study results in both the USA and the

\footnotetext{
* Correspondence: Jasper.vanRietPaap@radboudumc.nl

${ }^{1}$ Scientific Institute for Quality of Healthcare (IQ healthcare), Radboud University Medical Center, P.O. Box 9101, 6500 HB Nijmegen, The Netherlands

Full list of author information is available at the end of the article
}

Netherlands suggest that up to $40 \%$ of patients in need of palliative care do not receive evidence-based care [5]. Apparently, there is a wide 'gap' between the available scientific evidence and its use in daily practice [5].

The implementation of new evidence into daily practice is particularly challenging when complex changes are needed, cooperation between disciplines is required, or behaviour needs to be changed [6]. The use of traditional implementation strategies to convince professional care providers to use new evidence (such as identifying, synthesizing and disseminating evidence in journals, guidelines, continuing medical education and conferences) is apparently not sufficient to engineer changes in the complex systems of palliative care [5].

Yet, many studies that aim to improve palliative care have been performed. Often, these studies require much time investment and money from both 
the professional workforce as well as patients, which raises cost-effectiveness questions. It is therefore of utmost importance to synthesise and disseminate state-of-the-art scientific knowledge [7, 5]. The aim of this integrative review is to provide an overview of effective implementation strategies that have been used to improve the organisation of palliative care. As such, results of this review have been used in the EUfunded Seventh Framework IMPACT project (IMplementation of quality indicators for PAlliative Care sTudy) which aims to develop and tailor national and setting-specific strategies to improve the organisation of palliative care in Europe [8].

\section{Methods}

A review of available research literature was considered important to identify current knowledge about this topic.

The integrative review methodology summarizes past empirical and theoretical literature that uses diverse methodologies and study designs from a variety of sources in order to provide a comprehensive understanding of a complex health care problem [9]. Therefore, an iterative comparison and analysis of relevant publications about the implementation of strategies to improve the organisation of palliative care was conducted.

\section{Search strategy}

A comprehensive literature review was conducted, including Medline, CINAHL, British Nursing Index, PsycINFO, and by searching for grey literature [10] (e.g. literature that has not been published in peerreviewed literature). The search strategy was limited to English literature only, to publications that concerned palliative care for adults (aged 18 or above) and to publications that were published between 2000 and August 2011. Various search terms were used that referred to subject-specific keywords describing palliative care, as well as the type of implementation strategy and outcomes of the implementation, including synonyms and Medical SubHeadings (MeSH) to include all relevant literature. Table 1 provides an overview of the search terms (the search string is available in Additional file 1). Disease-specific search terms, such as cancer or dementia, were not included because the organisation of palliative care goes beyond a specific disease [11].

\section{Inclusion and exclusion criteria}

Publications were included when they described (1) improvements to the organisation of palliative care, (2) which implementation strategies were used, (3) how these strategies were implemented and (4) the effectiveness of these strategies. Publications were excluded when (1) no
Table 1 Overview of search terms

\begin{tabular}{lll}
\hline Palliative care & Implementation strategy & $\begin{array}{l}\text { Outcomes of } \\
\text { implementation }\end{array}$ \\
Terminal care & $\begin{array}{l}\text { Health plan } \\
\text { implementation }\end{array}$ & Quality of health care \\
Hospices & Programme development & Programme evaluation \\
Hospice care & Quality indicators & Quality \\
End-of-life care & Implementation strategy & Improvement \\
Comfort care & Programme evaluation & Change \\
Supportive care & Information dissemination & \\
Cancer care facilities & Information distribution & \\
Oncology service, & Organisational innovation & \\
hospital & & \\
& Organisation change & \\
& Diffusion of innovation & \\
& Educational models & \\
& Organisational models & \\
& Quality improvement &
\end{tabular}

abstract was available, (2) the implementation strategies were not directed at health care professionals or volunteers, (3) they were not directed at adult health care services or (4) educational curricula were developed.

\section{Data extraction and analysis}

Two of the authors (JvRP and RS, one with a background in nursing and health sciences and the other in sociology) independently screened title and abstract and reviewed the full-text articles of the included studies to identify implementation strategies to improve the organisation of palliative care. A data collection form was used to extract information about the country and year in which the study was published, study design, setting, type of disease, health care professionals involved, and type, description and impact of the implementation strategies used. Subsequently, implementation strategies were categorised into subgroups, according to the type of implementation strategy, similar to the approach of Grol and Grimshaw [5]. Data from the subgroup classification was coded and compiled into a matrix, whereby the effect of each implementation strategy was summarized as a significant improvement $(++)$, improvement $(+)$, mixed or limited effect $(+/-)$ or no effect $(-)$. To ensure the trustworthiness and rigor of the analysis, peer debriefing took place with the other authors throughout the entire process of data analysis.

\section{Results}

Study selection

Of the 2379 initially identified publications, 241 were selected for full-text assessment (Fig. 1). A first assessment 


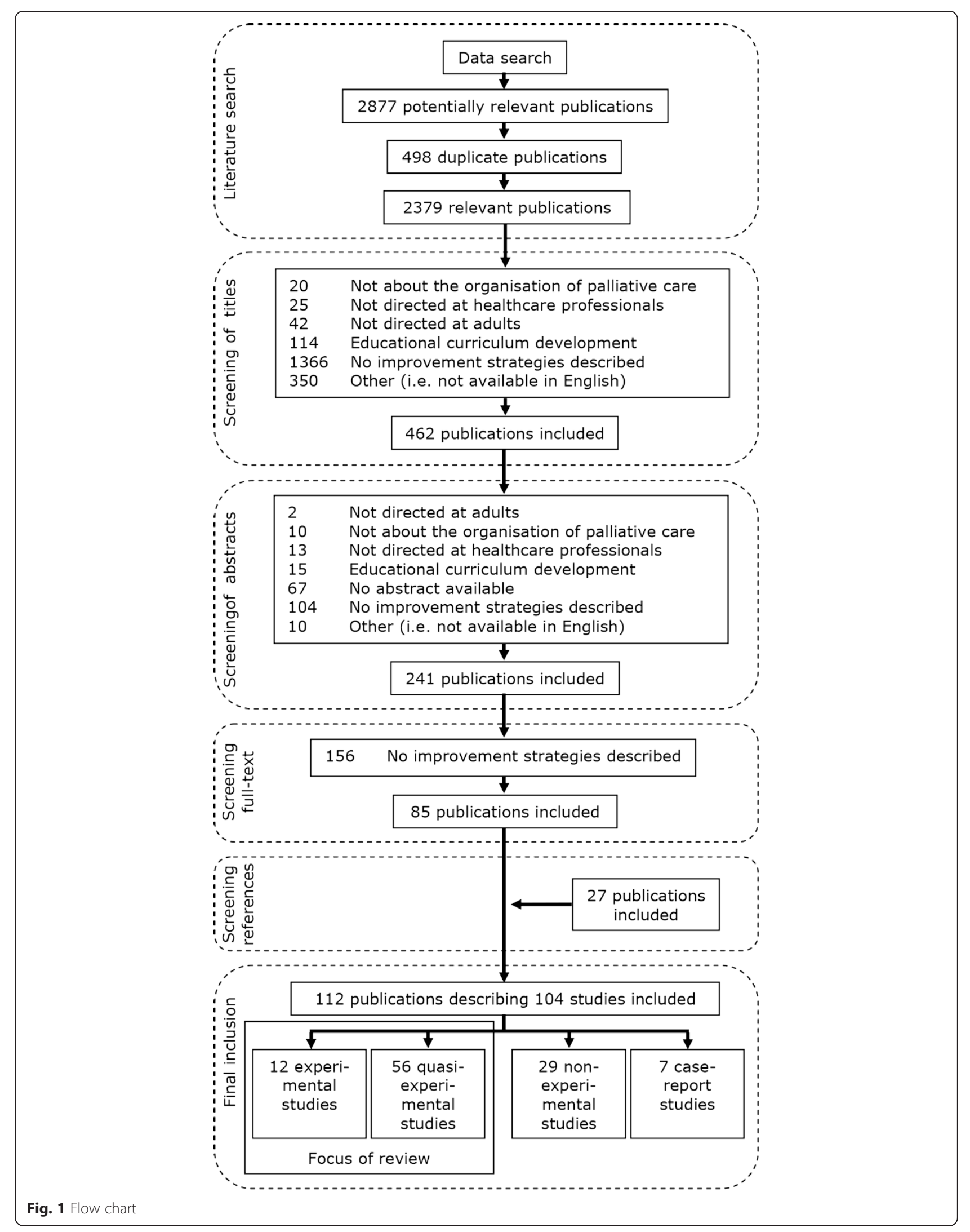


of the full-text of these publications revealed that 156 publications could be excluded, as they did not meet the inclusion criteria (for example, because there were no details given about the improvement strategy used). Reference lists of all publications eligible for inclusion as well as a hand search in grey literature databases revealed an additional 27 publications eligible for inclusion. The remaining publications represented a wide variety of research methods and designs: interviews, focus groups, strategy development designs, case descriptions, surveys, process evaluations, RCTs, pre-posttest interventions, review papers as well as theoretical papers. Because of the large number of identified studies, of which many were of low scientific quality and with incomparable outcome measures, only studies with an experimental $(n=12)$ or quasi-experimental $(n=56)$ study design were selected for further analysis.

\section{Characteristics of included studies}

A total of 17 single intervention studies and 51 multifaceted intervention studies were identified. Most studies were conducted in the USA $(n=29)$, UK $(n=19)$ and Australia $(n=8)$, but studies were also included from countries such as Japan, Taiwan, Italy and the Netherlands. Studies were conducted within the entire range of palliative care services, from home care services to advanced palliative care units in hospitals. Fifty-one studies were conducted in one setting (primary care: $n=2$, hospital: $n=38$, nursing home: $n=9$, hospice: $n=1$ and other: $n=1$ ) and 11 were conducted in multiple settings. For six studies, the type of setting could not be identified. Within the included studies, a large variety of professionals participated. Thirty-five studies were directed at a single type of professionals (e.g. nurses only), 29 at two or more different groups of professionals (e.g. nurses and physicians), and four studies did not report the target group of professionals.

\section{Strategies and its impact}

Additional file 2 provides a summarized description of the methodology, setting and country, number and type of participants, the implementation strategy and the impact of the strategy of each individual study. Table 2 provides an overview of the results of studies with an experimental or quasi-experimental study design.

\section{Educational strategies}

Two experimental and 12 quasi-experimental studies used different types of educational strategies to improve palliative care, including lectures [12-14], study days $[15,16]$, role play sessions $[17,18]$, interactive education $[19,20]$, educational outreach visits $[21]$ and computerfacilitated education [22-25]. Eight studies were targeted at a single profession, while six were targeted at multiple professionals. Four studies reported significant improvements, eight reported improvement, and two studies had limited or no effect.

\section{Process mapping}

One study used process mapping to improve the organisation of palliative care in a nursing home [26]. Before implementing the Liverpool Care Pathway, nursing home staff organized interdisciplinary team discussions where they answered the question, 'If your patient is diagnosed as dying at 10 am on Monday morning and they are in pain, what happens?' or in other words, 'What is the process?' in order to identify bottlenecks to be expected [26]. A repeated process measure post-implementation reduced the numbers of expected bottlenecks.

\section{Feedback}

One study addressed feedback to improve the organisation of palliative care [27]. In an RCT, patients completed a health-related quality of life questionnaire. In the intervention group, hospital physicians received automated feedback upon completion of this questionnaire. The RCT showed improved health-related quality of life in the intervention group compared to the control group.

\section{Multidisciplinary meetings}

One quasi-experimental study performed by Lilly et al. described family and multidisciplinary meetings to improve the communication and shared-decision making at the intensive care unit (ICU) in a hospital $[28,29]$. Pre- and post-intervention measurements showed that the use of such meetings reduced length of ICU stay.

\section{Mixed interventions}

Fifty-one studies used a combination of strategies. Half of these studies used a combination of solely educational strategies (for example, lecture combined with role play sessions) [30-58], while the other half combined a variety of strategies (for example, education combined with feedback and reminders) [59-86]. Nine studies had an experimental design. Based on the conclusions of the authors, there were 13 studies that had no or a limited effect on the specified outcomes, 21 studies that had a positive effect, and the remaining 17 studies reported a significant improvement.

\section{Discussion}

We made a comprehensive overview of the available literature in relation to strategies used to improve the organisation of palliative care. In total, 68 studies, representing an experimental or quasi-experimental study design, were discussed. These studies included educational strategies, process mapping, feedback, multidisciplinary meetings as well as mixed interventions. 
Table 2 Effect of strategies specified to setting

\begin{tabular}{|c|c|c|c|c|c|c|c|}
\hline Strategy & & No. & Primary care & Hospital & Nursing home & Hospice & Other, multiple or unknown settings \\
\hline \multirow[t]{9}{*}{$\begin{array}{l}\text { Single intervention } \\
\text { studies }\end{array}$} & Lecture & 3 & & Ke, $2008(++)$ & & $\begin{array}{l}\text { Schim, } \\
2006(+)\end{array}$ & Ersek, $2006(++)$ \\
\hline & Study day & 2 & & & & & Carr, 2003 (+); Dryden, 2009 (+) \\
\hline & Role play & 2 & & Hales, $2008(+)$ & & & Back, 2007 (+) \\
\hline & $\begin{array}{l}\text { Interactive } \\
\text { education }\end{array}$ & 2 & & Bruneau, $2004(-)$; Cooke, 2004 (+) & & & \\
\hline & Outreach visit & 1 & & & & & Newton, $2009(+)$ \\
\hline & $\begin{array}{l}\text { Computer-facilitated } \\
\text { education }\end{array}$ & 4 & & Hulsman, $2002(-)$; Jarabek, 2008 (++) & & & Ersek, $2008(++)$; Smith, $2010(+)$ \\
\hline & Process mapping & 1 & & & Taylor, 2007 (+) & & \\
\hline & Feedback & 1 & & Velikova, $2004(+)$ & & & \\
\hline & $\begin{array}{l}\text { Multidisciplinary } \\
\text { meetings }\end{array}$ & 1 & & Lilly, 2000; Lilly, 2003 (++) & & & \\
\hline \multirow[t]{2}{*}{$\begin{array}{l}\text { Multi-faceted intervention } \\
\text { studies }\end{array}$} & $\begin{array}{l}\text { Multi-educational } \\
\text { interventions }\end{array}$ & 25 & Reymond, 2005 (++) & $\begin{array}{l}\text { Bylund, } 2010 \text { (+/-); Furman, } 2006 \text { (+/-); } \\
\text { Betcher, } 2010(+) ; \text { Hall, } 2007(+) ; \text { Kinnane, } \\
2009 \text { (+); Razavi, } 2002 \text { and Delvaux, } 2004 \\
(+) ; \text { Fischer, } 2007 \text { (++); Kruse, } 2008(++) ; \\
\text { Bailey, } 2005 \text { (++); Fallowfield, } 2001 \text { (++); } \\
\text { Gueguen, } 2009 \text { (++);Sutherland, } 2007 \\
\text { (++); Yamagishi, } 2009 \text { (++) }\end{array}$ & $\begin{array}{l}\text { Weissman, } 2000(+) ; \\
\text { Weissman, } 2001(+)\end{array}$ & & $\begin{array}{l}\text { Bravemen, } 2001 \text { (+/-); Razavi, } 2003 \text { and } \\
\text { Lienard, } 2006 \text { and Lienard, } 2008 \text { and } \\
\text { Merckaert } 2008(+/-) \text {; Wilkinson, } 2008 \\
(+) ; \text { Finset, } 2003(+) \text {; Favre, } 2007(++) \text {; } \\
\text { Quinn, } 2008 \text { (++); Sullivan, } 2005 \text { (++); } \\
\text { Wilkinson, } 2002 \text { (++); Wilkinson, } \\
2003(++)\end{array}$ \\
\hline & Mixed interventions & 26 & Boakes, $2000(++)$ & $\begin{array}{l}\text { Butow, } 2008 \text { (-); Curtis, } 2011 \text { (-); } \\
\text { Fallowfield, } 2002 \text { and Jenkins, } 2002 \\
\text { and Shilling, } 2003 \text { and Fallowfield, } \\
2003 \text { (+/-); Hansen, } 2009 \text { (+/-); Hills, } \\
2009 \text { (+/-); Jacobs, } 2002 \text { (+/-); } \\
\text { McCormick, } 2010 \text { (+/-); Morgan, } \\
2010 \text { (+/-); Roila, } 2004 \text { (+/-); Kinley, } \\
2004 \text { (+); Lankshear, } 2010 \text { (+); Mirando, } \\
2005 \text { (+); Monteleoni, } 2004 \text { (+); Okon, } \\
2009 \text { (+); Smith, } 2009 \text { (+); Bookbinder, } \\
2005 \text { (++); Dauer, } 2006 \text { (++) }\end{array}$ & $\begin{array}{l}\text { Hanson, } 2005 \text { (+); Hockley, } \\
2010(+) ; \text { Lyon, } 2007(+) ; \\
\text { Reynolds, } 2004 \text { (+); Strumpf, } \\
2004 \text { (+); Keay, } 2003 \text { (++) }\end{array}$ & & Stacey, 2008 (+); Woo, 2011 (+) \\
\hline
\end{tabular}

++ significant improvement, + improvement, +/- mixed or limited effect, - no effect 
For this review, all reported outcome measures in the identified studies were extracted. These measures included several patient outcome data items (e.g. assessment of the percentage of patients in pain following an educational session about pain treatment) as well as data concerning the process of care (e.g. the frequency of patient referral to specialist care following the introduction of a new referral form), making comparisons of outcomes impossible. However, the aim of all included studies was to improve the organisation of palliative care. We therefore generalized the outcomes to the degree in which they aimed to improve the organisation of palliative care.

Fifty-three studies, covering all strategies identified, reported that their study resulted in improving the organisation of palliative care. Eleven studies showed improvements for some of the characteristics targeted (four multieducational and seven multi-faceted strategies), and four studies reported limited or no improvements (one using interactive education, one using computer-facilitated education and two multi-faceted strategies). The studies with a mixed or limited result on improving the organisation of palliative care were primarily conducted in one setting (hospital) and directed at one professional group. This stipulates the challenges that are encountered when implementing new evidence in complex environments such as a hospital as well as the importance of the multidisciplinary and interdisciplinary character of palliative care.

The different strategies identified in this review have been described in other fields in health care. In a review by Grol and Grimshaw, for example, large conferences and courses showed mixed effects, small group interactive education showed positive effects, educational outreach showed positive effects, feedback showed mixed effects and the used of mixed interventions often resulted in better results compared to single intervention studies [5]. Reviews that focused on one strategy type, for example, on audit and feedback [87], printed educational materials [88] or educational outreach visits [89], all had similar findings. One reason for the primarily positive findings of the studies identified in this review might be the fact that participants in a quality improvement project perform better as a result of knowing they are a study object (Hawthorne effect) [90]. Another reason might be that effects were often measured immediately after the intervention, so we do not know if the effects were sustained. Finally, only a few studies $(n=12)$ used a randomised controlled design, which is often considered to be the gold standard in research [91], compared to other designs. RCTs require significant time and funding and expert research guidance, and particularly, in palliative care populations, they are scarce because of recruitment restrictions, high attrition, (selection) bias, lack of blinding, confounding and small sample sizes [92, 91]. Many of these aspects, however, are also relevant in studies with a quasi-experimental, non-experimental or case-study design. The studies that were included in this review might, therefore, not represent the strongest designs to test improvement strategies.

The included studies were conducted in a variety of settings (e.g. hospitals, nursing homes, hospices and primary care facilities). The provision of palliative care within these settings may vary depending on the patient group. Patients with cancer, for example, have a different disease trajectory, and other symptoms and needs than persons with dementia [93, 94]. Despite these differences, there are many similarities regarding the organisation and multidisciplinary character of palliative care. For all chronic, lifethreatening conditions, palliative care entails a patientcentred approach in which multidimensional interventions related to actual and future problems, needs and preferences are made.

The WHO definition of palliative care is therefore applicable for all patient groups [3]. The European Association of Palliative Care illustrates this by recommending a common approach for palliative care across settings $[95,96]$. In addition, 40 international experts agreed that there is no need to formulate disease-specific quality criteria for the organisation of palliative care [97]. However, this does not mean that there is ample evidence regarding effective strategies to improve (the organisation of) palliative care in the different settings. Hall et al., for example, described that there is limited evidence for palliative care service delivery for residents of care homes for older people [98]. This illustrates the necessity to further improve the field of implementation science, in particular, in underdeveloped areas such as palliative care for persons with dementia.

Quality improvement projects often require investments of time and money from both the professional workforce and patients. It is important that the evidence of effective strategies is used to improve daily clinical practice. However, researchers and professionals often have different cultures, values, timelines, goals and rewards [99]. Even when the intervention is well-designed, real-world contextual factors may prevent the intervention from being realized. Implementation of evidence-based and best practices should therefore always be guided by a step-by-step model in order to identify the problem, barriers and facilitators and tailored strategies to solve the problem [100]. Integrated knowledge translation can then be used as a bridge in closing the gap between what we know and what we do [101].

The results of this review were used in the EUfunded Seventh Framework IMPACT project. An intervention study investigating improvement projects with pre- and post-test evaluations was performed in 
40 services providing palliative care across Europe (including hospitals, nursing homes, hospices and primary care facilities). In this study, quality indicators were used to identify potential areas to improve the organisation of palliative care. Subsequently, Grol's implementation of change model [100] was used to guide the services in their quality improvements. The strategies described in this review were used as an example and if possible also as actual strategies regarding how to change the organisation of palliative care.

\section{Strengths and limitations}

This is one of the first reviews that provides an overview of implementation strategies used to improve the organisation of palliative care. The results of this review can be used as a starting point for further research. However, some limitations should be taken into account. Firstly, this review used the integrative review methodology. Although this approach allows for the combination of diverse methodologies (including non-experimental research), only studies with an experimental and quasi-experimental design were included because of the unexpected high number of publications on the highest evidence level. Since a variety of methods was used in these studies, a quantitative comparison of effect size was considered impossible. Secondly, because it was the aim of this review to provide an overview of strategies used to improve the organisation of palliative care rather than the effectiveness, we did not assess each individual study for risk of bias or effect estimates. The effects of the strategies presented in this paper should therefore be interpreted with caution. Thirdly, we have limited the search strategy to English literature only. Although publications have been included from non-English speaking countries such as Japan and Italy, it is likely that we have missed potentially interesting publications from countries that often publish in their own language. Fourthly, there is no generic set of search terms to identify literature about improvement strategies, despite the fact that improvements are now being recognized as a science [102, 103]. Although we have captured a broad selection of literature with our search strategy, it is possible that it did not identify all available publications on this topic.

\section{Conclusion}

This review provides an overview of the available literature in relation to strategies used to improve the organisation of palliative care. The identified studies described educational strategies, process mapping, feedback, multidisciplinary meetings and multi-faceted interventions. Future research, with more rigid designs, proper duration, control and blinding are necessary to identify and improve scientific evidence regarding the optimal strategies to improve the organisation of palliative care.

\section{Additional files}

\section{Additional file 1: Search string. The search strings for Medline,} CINAHL, British Nursing Index and PsycINFO. (PDF $57 \mathrm{~kb}$ )

Additional file 2: Description studies. Summarized description of the methodology, setting and country, number and type of participants, the implementation strategy, and the impact of the strategy of each individual study. (PDF $182 \mathrm{~kb}$ )

\section{Competing interests}

The authors declare that they have no competing interests.

\section{Authors' contributions}

YE and MVD are responsible for the design of the study. JVRP and RS equally contributed in the development of the search strategy, selection procedure and analysis of included studies. JVRP drafted the first manuscript. YE, MVD, KV, WM, MH, WL and RS provided extensive feedback to different versions of the manuscript. All authors approved the final manuscript.

\section{Acknowledgements}

This review is part of the larger IMPACT project (IMplementation of quality indicators in PAlliative Care sTudy). The IMPACT project received funding from the European Union's Seventh Framework Programme FP7/2007-2013 under grant agreement no. 258883. We thank all participating researchers involved in the IMPACT consortium for their support. Special thanks go to the library staff of both the Radboud university medical center and the Norwegian University of Science and Technology, who provided exhaustive feedback, assistance and support in the development of the search strategy.

\section{Author details}

${ }^{1}$ Scientific Institute for Quality of Healthcare (IQ healthcare), Radboud University Medical Center, P.O. Box 9101, 6500 HB Nijmegen, The Netherlands. ${ }^{2}$ Nijmegen Alzheimer Centre, Radboud University Medical Center, P.O. Box 9101, 6500 HB Nijmegen, The Netherlands. ${ }^{3}$ Kalorama Foundation, Nijmegen, The Netherlands. ${ }^{4}$ European Palliative Care Research Centre, Department of Cancer Research and Molecular Medicine, Faculty of Medicine, Norwegian University of Science and Technology, P.O. Box 8905, N-7491 Trondheim, Norway. ${ }^{5}$ Centre for Health Practice Innovation, Griffith Health Institute, Griffith University, 170 Kessels Road, Nathan, Brisbane, Australia. ${ }^{6}$ Regional Centre for Excellence in Palliative Care Department of Oncology, Oslo University Hospital, P.O. Box 4956, Nydalen 0424, Oslo, Norway. ${ }^{7}$ Department of Palliative Medicine, Poznan University of Medical Sciences, 61-245 Poznan, Poland. ${ }^{8}$ Department of Anaesthesiology, Pain and Palliative Medicine, Radboud University Medical Center, P.O. Box 9101, 6500 HB Nijmegen, The Netherlands.

Received: 22 December 2014 Accepted: 11 July 2015

Published online: 26 July 2015

\section{References}

1. Ouwens M, Wollersheim H, Hermens R, Hulscher M, Grol R. Integrated care programmes for chronically ill patients: a review of systematic reviews. Int J Qual Health Care. 2005;17(2):141-6.

2. Lynn J, Adamsom D. Living well at the end of life: adapting health care to serious chronic illness in old age, Rand Health White Paper WP137 edition. 2003.

3. World Health Organization. Palliative care. http://www.who.int/cancer/ palliative/en/.

4. Sepulveda C, Marlin A, Yoshida T, Ullrich A. Palliative care: the World Health Organization's global perspective. J Pain Symptom Manage. 2002;24(2):91-6

5. Grol R, Grimshaw J. From best evidence to best practice: effective implementation of change in patients' care. Lancet. 2003;362(9391):1225-30.

6. Grol RP, Bosch MC, Hulscher ME, Eccles MP, Wensing M. Planning and studying improvement in patient care: the use of theoretical perspectives. Milbank Q. 2007:85(1):93-138.

7. Grimshaw JM, Eccles MP, Walker AE, Thomas RE. Changing physicians' behavior: what works and thoughts on getting more things to work. J Contin Educ Health Prof. 2002;22(4):237-43. 
8. van Riet PJ, Engels $Y$, lliffe $S$, Radbruch L, Kaasa S, Chattat $R$, et al. Improving the organization of palliative care by implementing quality indicators and national and setting-specific interventions: study protocol of the IMPACT project. Progr Palliat Care. 2014;22(4):201-5.

9. Whittemore $\mathrm{R}$, Knafl K. The integrative review: updated methodology. J Adv Nurs. 2005;52(5):546-53.

10. Cook AM, Finlay IG, Edwards AG, Hood K, Higginson IJ, Goodwin DM, et al. Efficiency of searching the grey literature in palliative care. J Pain Symptom Manage. 2001;22(3):797-801.

11. van der Steen JT, Radbruch L, Hertogh CM, de Boer ME, Hughes JC, Larkin $\mathrm{P}$, et al. White paper defining optimal palliative care in older people with dementia: a Delphi study and recommendations from the European Association for Palliative Care. Palliat Med. 2014;28(3):197-209.

12. Ke L-S, Chiu T-Y, Hu W-Y, Lo S-S. Effects of educational intervention on nurses' knowledge, attitudes, and behavioral intentions toward supplying artificial nutrition and hydration to terminal cancer patients. Support Care Cancer. 2008;16(11):1265-72.

13. Ersek M, Kraybukk B, Hansen N. Evaluation of a train-the-trainer program to enhance hospice and palliative care in nursing homes J Hospice Palliat Nurs. 2006;8(1):42-9.

14. Schim SM, Doorenbos AZ, Borse NN. Enhancing cultural competence among hospice staff. Am J Hosp Palliat Care. 2006;23(5):404-11.

15. Carr ECJ, Brockbank K, Barrett RF. Improving pain management through interprofessional education: evaluation of a pilot project. Learn Health Soc Care. 2003;2(1):6-17.

16. Dryden $\mathrm{H}$, Addicott $\mathrm{R}$. Evaluation of a pilot study day for healthcare assistants and social care officers. Int J Palliat Nurs. 2009;15(1):6-11.

17. Back AL, Arnold RM, Baile WF, Fryer-Edwards KA, Alexander SC, Barley GE, et al. Efficacy of communication skills training for giving bad news and discussing transitions to palliative care. Arch Intern Med. 2007;167(5):453-60.

18. Hales BM, Hawryluck L. An interactive educational workshop to improve end of life communication skills. J Contin Educ Health Prof. 2008;28(4):241-8.

19. Bruneau BMS, Ellison GTH. Palliative care stress in a UK community hospital: evaluation of a stress-reduction programme. Int J Palliat Nurs. 2004;10(6):296-304.

20. Cooke L, Smith-Idell C, Dean G, Gemmill R, Steingass S, Sun V, et al. "Research to Practice": a practical program to enhance the use of evidence-based practice at the unit level. Oncol Nurs Forum. 2004;31(4):825-32

21. Newton J, Clark R, Ahlquist P. Evaluation of the introduction of an advanced care plan into multiple palliative care settings. Int J Palliat Nurs. 2009;15(11):554-61.

22. Ersek M, Wood BB. Development and evaluation of a Nursing Assistant Computerized Education Programme. Int J Palliat Nurs. 2008;14(10):502-9.

23. Hulsman RL, Ros WJ, Winnubst JA, Bensing JM. The effectiveness of a computer-assisted instruction programme on communication skills of medical specialists in oncology. Med Educ. 2002;36(2):125-34.

24. Jarabek B, Jama A, Cha S. Use of palliative care order set to improve resident comfort with symptom management in palliative care. Palliat Med. 2008;22(4):343-9.

25. Smith S, Arnold G, Kinghorn S, Poppleton A. Using e-learning to develop communication skills when assessing patients' end of life needs. Nurs Times. 2010;106(41):20-2.

26. Taylor AJ, Randall C. Process mapping: enhancing the implementation of the Liverpool Care Pathway. Int J Palliat Nurs. 2007;13(4):163-7.

27. Velikova G, Booth L, Smith AB, Brown PM, Lynch P, Brown JM, et al Measuring quality of life in routine oncology practice improves communication and patient well-being: a randomized controlled trial. J Clin Oncol. 2004;22(4):714-24.

28. Lilly CM, De Meo DL, Sonna LA, Haley KJ, Massaro AF, Wallace RF, et al. An intensive communication intervention for the critically ill. Am J Med. 2000;109(6):469-75.

29. Lilly CM, Sonna LA, Haley KJ, Massaro AF. Intensive communication: four-year follow-up from a clinical practice study. Crit Care Med. 2003;31(5 Suppl):S394-9

30. Yamagishi A, Tanaka F, Morita T. Artificial hydration therapy for terminally ill cancer patients: a nurse-education intervention. J Pain Symptom Manage. 2009;38(3):358-64.

31. Wilkinson S, Leliopoulou C, Gambles M, Roberts A. Can intensive threeday programs improve nurses' communication skills in cancer care? Psychooncology. 2003;12(8):747-59.
32. Wilkinson SM, Gambles M, Roberts A. The essence of cancer care: the impact of training on nurses' ability to communicate effectively. J Adv Nurs. 2002;40(6):731-8.

33. Weissman DE, Griffie J, Muchka S, Matson S. Improving pain management in long-term care facilities. J Palliat Med. 2001;4(4):567-73.

34. Delvaux N, Razavi D, Marchal S, Bredart A, Farvacques C, Slachmuylder $J$. Effects of a 105 hours psychological training program on attitudes, communication skills and occupational stress in oncology: a randomised study. Br J Cancer. 2004;90(1):106-14.

35. Kruse BG, Melhado LW, Convertine L, Stecher J. Evaluating strategies for changing acute care nurses' perceptions on end-of-life care. Am J Hosp Palliat Care. 2008;25(5):389-97.

36. Lienard A, Merckaert I, Libert Y, Delvaux N, Marchal S, Boniver J, et al. Factors that influence cancer patients' anxiety following a medical consultation: impact of a communication skills training programme for physicians. Ann Oncol. 2006;17(9):1450-8.

37. Razavi D, Merckaert I, Marchal S, Libert Y, Conradt S, Boniver J, et al. How to optimize physicians' communication skills in cancer care: results of a randomized study assessing the usefulness of posttraining consolidation workshops. J Clin Oncol. 2003;21(16):3141-9.

38. Razavi D, Delvaux N, Marchal S, Durieux JF, Farvacques C, Dubus L, et al. Does training increase the use of more emotionally laden words by nurses when talking with cancer patients? A randomised study. Br J Cancer. 2002;87(1):1-7.

39. Wilkinson S, Perry R, Blanchard K, Linsell L. Effectiveness of a three-day communication skills course in changing nurses' communication skills with cancer/palliative care patients: a randomised controlled trial. Palliat Med. 2008;22(4):365-75.

40. Betcher DK. Elephant in the room project: improving caring efficacy through effective and compassionate communication with palliative care patients. Medsurg Nurs. 2010;19(2):101-5.

41. Bailey FA, Burgio KL, Woodby LL, Williams BR, Redden DT, Kovac SH, et al. Improving processes of hospital care during the last hours of life. Arch Intern Med. 2005;165(15):1722-7.

42. Bravemen C, Rodrigues C. Pain and symptom management. Performance improvement in pain management for home care and hospice programs. Am J Hospice Palliat Care. 2001;18(4):257-63. 88, 1 p.

43. Bylund C, Brown R, Gueguen J. The implementation and assessment of a comprehensive communication skills training curriculum for oncologists. Psychooncology. 2010;19(6):583-93.

44. Favre N, Despland JN, de Roten Y, Drapeau M, Bernard M, Stiefel F. Psychodynamic aspects of communication skills training: a pilot study. Support Care Cancer. 2007;15(3):333-7.

45. Fallowfield L, Saul J, Gilligan B. Teaching senior nurses how to teach communication skills in oncology. Cancer Nurs. 2001:24(3):185-91.

46. Finset $\mathrm{A}$, Ekeberg $\mathrm{O}$, Eide $\mathrm{H}$, Aspegren K. Long term benefits of communication skills training for cancer doctors. Psychooncology. 2003;12(7):686-93.

47. Fischer GS, Arnold RM. Feasibility of a brief workshop on palliative care communication skills for medical interns. J Palliat Med. 2007;10(1):19-23.

48. Furman CD, Head B, Lazor B, Casper B, Ritchie CS. Evaluation of an educational intervention to encourage advance directive discussions between medicine residents and patients. J Palliat Med. 2006:9(4):964-7.

49. Gueguen JA, Bylund CL, Brown RF, Levin TT, Kissane DW. Conducting family meetings in palliative care: themes, techniques, and preliminary evaluation of a communication skills module. Palliat Support Care. 2009;7(2):171-9.

50. Hall P, Weaver L, Gravelle D, Thibault H. Developing collaborative personcentred practice: a pilot project on a palliative care unit. J Interprof Care. 2007;21(1):69-81.

51. Kinnane NA, Waters T, Aranda S. Evaluation of a pilot 'peer support' training programme for volunteers in a hospital-based cancer information and support centre. Support Care Cancer. 2011:19(1):81-90.

52. Quinn K, Hudson P, Ashby M, Thomas K. "Palliative care: the essentials": evaluation of a multidisciplinary education program. J Palliat Med. 2008;11(8):1122-9.

53. Reymond L, Charles M, Israel F, Read T, Treston P. A strategy to increase the palliative care capacity of rural primary health care providers. Aust J Rural Health. 2005:13(3):156-61.

54. Sullivan AM, Lakoma MD, Billings JA, Peters AS, Block SD. Teaching and learning end-of-life care: evaluation of a faculty development program in palliative care. Acad Med. 2005;80(7):657-68. 
55. Sutherland G, Hegarty S, White V, Coffin J, Jefford M. Development and evaluation of a brief, peer-led communication skills training program for cancer clinicians. Asia-Pacific. J Clin Oncol. 2007;3:207-13.

56. Weissman DE, Griffie J, Muchka S, Matson S. Building an institutional commitment to pain management in long-term care facilities. J Pain Symptom Manage. 2000;20(1):35-43.

57. Lienard A, Merckaert I, Libert Y, Delvaux N, Marchal S, Boniver J, et al. Factors that influence cancer patients' and relatives' anxiety following a three-person medical consultation: impact of a communication skills training program for physicians. Psychooncology. 2008;17(5):488-96.

58. Merckaert I, Libert Y, Delvaux N, Marchal S, Boniver J, Etienne AM, et al. Factors influencing physicians' detection of cancer patients' and relatives' distress: can a communication skills training program improve physicians' detection? Psychooncology. 2008;17(3):260-9.

59. Butow P, Cockburn J, Girgis A, Bowman D, Schofield P, D'Este C, et al. Increasing oncologists' skills in eliciting and responding to emotional cues: evaluation of a communication skills training program. Psychooncology. 2008;17(3):209-18.

60. Curtis JR, Nielsen EL, Treece PD, Downey L, Dotolo D, Shannon SE, et al. Effect of a quality-improvement intervention on end-of-life care in the intensive care unit: a randomized trial. Am J Respir Crit Care Med. 2011;183(3):348-55.

61. Fallowfield $L$, Jenkins $V$, Farewell $V$, Saul J, Duffy A, Eves R. Efficacy of a Cancer Research UK communication skills training model for oncologists: a randomised controlled trial. Lancet. 2002;359(9307):650-6.

62. Fallowfield $L$, Jenkins V, Farewell V, Solis-Trapala I. Enduring impact of communication skills training: results of a 12-month follow-up. Br J Cancer. 2003;89(8):1445-9.

63. Shilling $V$, Jenkins $V$, Fallowfield $L$. Factors affecting patient and clinician satisfaction with the clinical consultation: can communication skills training for clinicians improve satisfaction? Psychooncology. 2003;12(6):599-611.

64. Hanson LC, Reynolds KS, Henderson M, Pickard CG. A quality improvement intervention to increase palliative care in nursing homes. J Palliat Med. 2005;8(3):576-84.

65. Roila F. Transferring scientific evidence to oncological practice: a trial on the impact of three different implementation strategies on antiemetic prescriptions. Support Care Cancer. 2004;12(6):446-53.

66. Boakes J, Gardner D, Yuen K, Doyle S. General practitioner training in palliative care: an experiential approach. J Palliat Care. 2000;16(2):11-9.

67. Bookbinder M, Blank AE, Arney E, Wollner D, Lesage P, McHugh M, et al. Improving end-of-life care: development and pilot-test of a clinical pathway. J Pain Symptom Manage. 2005:29(6):529-43.

68. Dauer LT, Kelvin JF, Horan CL, St GJ. Evaluating the effectiveness of a radiation safety training intervention for oncology nurses: a pretestintervention-posttest study. BMC Med Educ. 2006;6:32.

69. Hansen L, Goodell TT, DeHaven J, Smith M. Nurses' perceptions of end-oflife care after multiple interventions for improvement. Am J Crit Care. 2009;18(3):263-71.

70. Hills M, Albarran JW. Evaluating last offices care and improving services offered to newly bereaved relatives. Nurs Times. 2009;105(23):14-6.

71. Hockley J, Watson J, Oxenham D. The integrated implementation of two end-of-life care tools in nursing care homes in the UK: an in-depth evaluation. Palliat Med. 2010;24(8):828-38.

72. Jacobs LG, Bonuck K, Burton W. Can "palliative care reports" improve end-of-life care for hospitalized patients? J Pain Symptom Manage. 2002;24(3):299-311.

73. Kinley J, Brennan S. Changing practice: use of audit to change oral care practice. Int J Palliat Nurs. 2004;10(12):580-7.

74. Keay TJ, Alexander C, McNally K, Crusse E, Eger RE. Nursing home physician educational intervention improves end-of-life outcomes. J Palliat Med. 2003:6(2):205-13.

75. Lankshear S, Brierley JD, Imrie K, Yurcan M. Changing physician practice: an evaluation of knowledge transfer strategies to enhance physician documentation of cancer stage. Healthc Q. 2010;13(1):84-92.

76. Lyon C. Advance care planning for residents in aged care facilities: what is best practice and how can evidence-based guidelines be implemented? Int J Evid Based Healthc. 2007:5(4):450-7.

77. McCormick AJ, Curtis JR, Stowell-Weiss P, Toms C, Engelberg R. Improving social work in intensive care unit palliative care: results of a quality improvement intervention. J Palliat Med. 2010;13(3):297-304.

78. Mirando S, Davies PD, Lipp A. Introducing an integrated care pathway for the last days of life. Palliat Med. 2005;19(1):33-9.
79. Monteleoni C, Clarke E. Using rapid-cycle quality improvement methodology to reduce feeding tubes in patients with advanced dementia: before and after study. BMJ. 2004;329(7464):491-4.

80. Morgan J. How to improve services for dying patients in critical care: adapting protocols. Nurs Times. 2010;106(4):16-8.

81. Reynolds KS. End-of-life care in nursing home settings: University of North Carolina at Chapel Hill. 2004.

82. Smith EML, Bakitas MA, Homel P, Fadul C, Meyer L, Skalla K, et al. Using quality improvement methodology to improve neuropathic pain screening and assessment in patients with cancer. J Cancer Educ. 2009;24(2):135-40.

83. Stacey D, Chambers S, Jacobsen M. Overcoming barriers to cancer-helpline professionals providing decision support for callers: an implementation study. Oncol Nurs Forum. 2008:35(6):961-9.

84. Strumpf NE, Tuch H, Stillman D, Parrish P, Morrison N. Implementing palliative care in the nursing home. Ann Long Term Care. 2004;12(11):35-41.

85. Woo J, Cheng JO, Lee J, Lo R, Hui E, Lum C, et al. Evaluation of a continuous quality improvement initiative for end-of-life care for older noncancer patients. J Am Med Dir Assoc. 2011;12(2):105-13.

86. Okon T, Lutz P, Liang H. Improved pain resolution in hospitalized patients through targeting of pain mismanagement as medical error. J Pain Symptom Manage. 2009;37(6):1039-49.

87. Ivers N, Jamtvedt G, Flottorp S, Young JM, Odgaard-Jensen J, French SD, et al. Audit and feedback: effects on professional practice and healthcare outcomes. Cochrane Database Syst Rev. 2012;6:CD000259.

88. Giguere A, Legare F, Grimshaw J, Turcotte S, Fiander M, Grudniewicz A et al. Printed educational materials: effects on professional practice and healthcare outcomes. Cochrane Database Syst Rev. 2012;10:CD004398.

89. O'Brien MA, Rogers S, Jamtvedt G, Oxman AD, Odgaard-Jensen J, Kristoffersen DT, et al. Educational outreach visits: effects on professional practice and health care outcomes. Cochrane Database Syst Rev. 2007:4:CD000409.

90. Braunholtz DA, Edwards SJ, Lilford RJ. Are randomized clinical trials good for us (in the short term)? Evidence for a "trial effect". J Clin Epidemiol. 2001:54(3):217-24

91. Carlson MD, Morrison RS. User's guide to research in palliative care: why is a new series needed? J Palliat Med. 2008;11(9):1258-61.

92. Higginson IJ, Evans CJ, Grande G, Preston N, Morgan M, McCrone P, et al. Evaluating complex interventions in end of life care: the MORECare statement on good practice generated by a synthesis of transparent expert consultations and systematic reviews. BMC Med. 2013;11:111.

93. Teunissen SC, Wesker W, Kruitwagen C, de Haes HC, Voest EE, de Graeff A. Symptom prevalence in patients with incurable cancer: a systematic review. J Pain Symptom Manage. 2007;34(1):94-104.

94. Osse BH, Vernooij-Dassen MJ, Schade E, Grol RP. The problems experienced by patients with cancer and their needs for palliative care. Support Care Cancer. 2005;13(9):722-32.

95. Radbruch L, Payne S. White paper on standards and norms for hospice and palliative care in Europe: part 1. Eur J Palliat Care. 2009;16:278-89.

96. Radbruch L, Payne S. White paper on standards and norms for hospice and palliative care in Europe: part 2. Eur J Palliat Care. 2010;17:22-33.

97. van Riet Paap J, Vernooij-Dassen M, Droes RM, Radbruch L, Vissers K, Engels $Y$, et al. Consensus on quality indicators to assess the organisation of palliative cancer and dementia care applicable across national healthcare systems and selected by international experts. BMC Health Serv Res. 2014;14:396

98. Hall S, Kolliakou A, Petkova H, Froggatt K, Higginson IJ. Interventions for improving palliative care for older people living in nursing care homes. Cochrane Database Syst Rev. 2011;3:CD007132.

99. Kothari A, Regan S, Gore D, Valaitis R, Garcia J, Manson H, et al. Using an integrated knowledge translation approach to build a public health research agenda. Health Res Pol Syst. 2014;12(1):6.

100. Grol R, Wensing M, Eccles MP. Improving patient care: the implementation of change in clinical practice. Edingburg: Elsevier; 2005.

101. Graham ID, Tetroe JM. Getting evidence into policy and practice: perspective of a health research funder. J Can Acad Child Adolesc Psychiatry. 2009;18(1):46-50.

102. Wensing M, Grimshaw JM, Eccles MP. Does the world need a scientific society for research on how to improve healthcare? Implement Sci. 2012;7:10.

103. Marshall M, Pronovost P, Dixon-Woods M. Promotion of improvement as a science. Lancet. 2013:381(9864):419-21. 